\title{
Cervical Spondylotic Myelopathy: An Updated Review
}

\author{
George P Lee, $M D^{1^{*}}$, Bhaveshkumar Ahir, PhD', Nauman Chaudhry, $M D^{1}$ and Herbert H Engelhard, MD, \\ PhD ${ }^{1,3}$
}

${ }^{1}$ Department of Neurosurgery, University of Illinois at Chicago, Illinois, USA

${ }^{2}$ Department of Medicine, University of Illinois at Chicago, Chicago, Illinois, USA

${ }^{3}$ Department of Bioengineering, University of Illinois at Chicago, Chicago, Illinois, USA

*Corresponding author: Dr. George P Lee, Department of Neurosurgery, University of Illinois at Chicago, 912 South Wood Street, Chicago, Illinois, USA, Tel: (630)-800-6888, Fax: (312)-355-2049

\begin{abstract}
Cervical spondylotic myelopathy (CSM) is a common cause of spinal cord dysfunction. The degenerative disease can cause serious neurological symptoms that can significantly affect the quality of life. The heterogenous presentation of CSM and a lack of a single comprehensive outcome instrument can make the management of suspected CSM very difficult. Despite the advances in surgical techniques to treat CSM, the indications to do surgery remain controversial, particularly in older individuals who commonly present with the disease. There is also debate on the optimal surgical approach to treat CSM, and most neurosurgeons remain unfamiliar with the evaluation tools that drive economic health care as a result of the surgical procedures. Here, the scientific literature was carried out using PubMed with the following keywords: cervical spondylotic myelopathy, anterior, posterior, anterior-posterior, elderly, cost-utility analyses. The bibliographies of these papers were also reviewed to yield additional papers of high significance. The goal of this review is to provide insight in to the surgical outcomes, preoperative management decisions, elderly population, and the cost-effectiveness of the types of surgery in relation to cost per quality-adjusted life year (QALY) gained.
\end{abstract}

\section{Keywords}

Cervical spondylotic myelopathy, ACDF, Corpectomy, Hybrid decompression, Laminectomy, Elderly, Cost-utility analysis

\section{Introduction}

Cervical spondylotic myelopathy (CSM) is a common spinal disorder seen in persons older than 55 years of age [1]. The annual incidence of myelopathy as a result of cervical spondylosis is approximately 4 per 100,000
$[2,3]$. CSM remains a challenge for neurosurgeons because the timing, indications, and surgical approaches continue to be controversial. There are also concern for surgical outcomes in the elderly population, and the cost-benefit ratio of the different surgical procedures.

The pathophysiology of CSM is a multifactorial process that can be attributed to static and dynamic factors $[4,5]$. Static factors include degenerative changes such as vertebral body osteophyte formation, or degenerative changes along the facet or uncovertebral joints. Dynamic factors relate to repetitive movements of the neck that can exacerbate spinal cord compression. For example, flexion of the cervical spine can be compressed against osteophytic spurs protruding into the spinal canal, or extension of the neck can cause buckling of the ligamentum flavum. In either case, static and dynamic factors can result in cervical spinal cord compression producing neurological symptoms.

\section{Clinical Features}

The natural history of CSM is variable [6]. Certain individuals may have a gradual decline whereas others may experience a long quiescent period [7]. Still others may have an acute or subacute onset after a fall or neck injury [8]. The clinical presentation of CSM can also be variable since there is no well-defined pattern. However, the presentation can be thought of as a result of an upper and/or lower motor neuron injury since the spinal cord is compressed. In the upper motor neuron division, the lateral corticospinal tracts (voluntary limb control) and the posterior and anterior spinocerebel- 


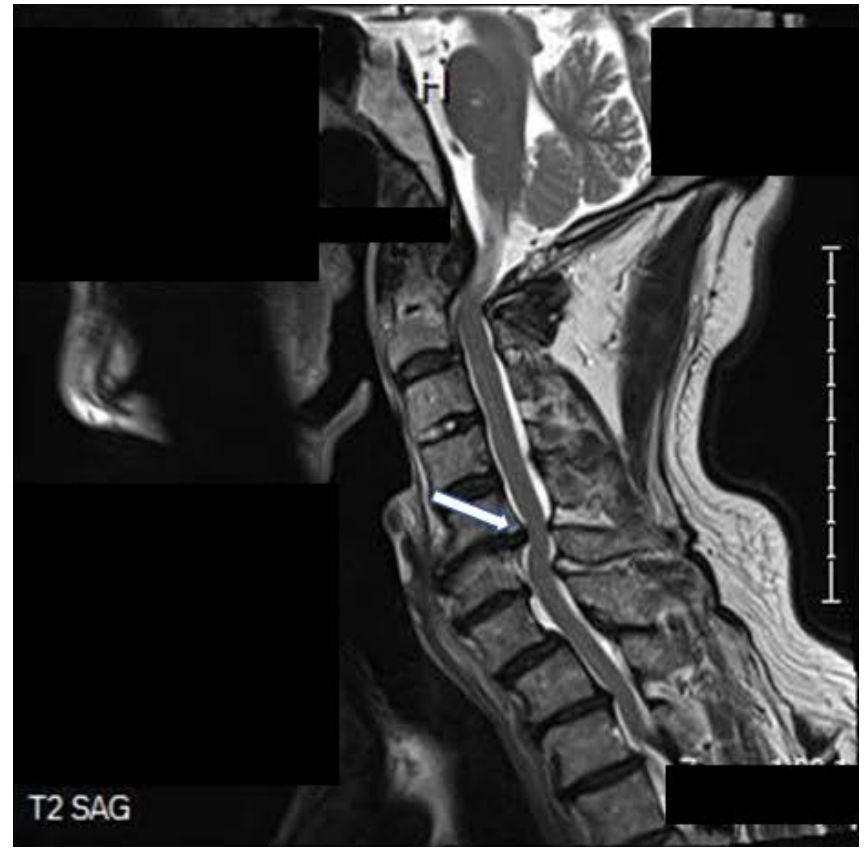

A

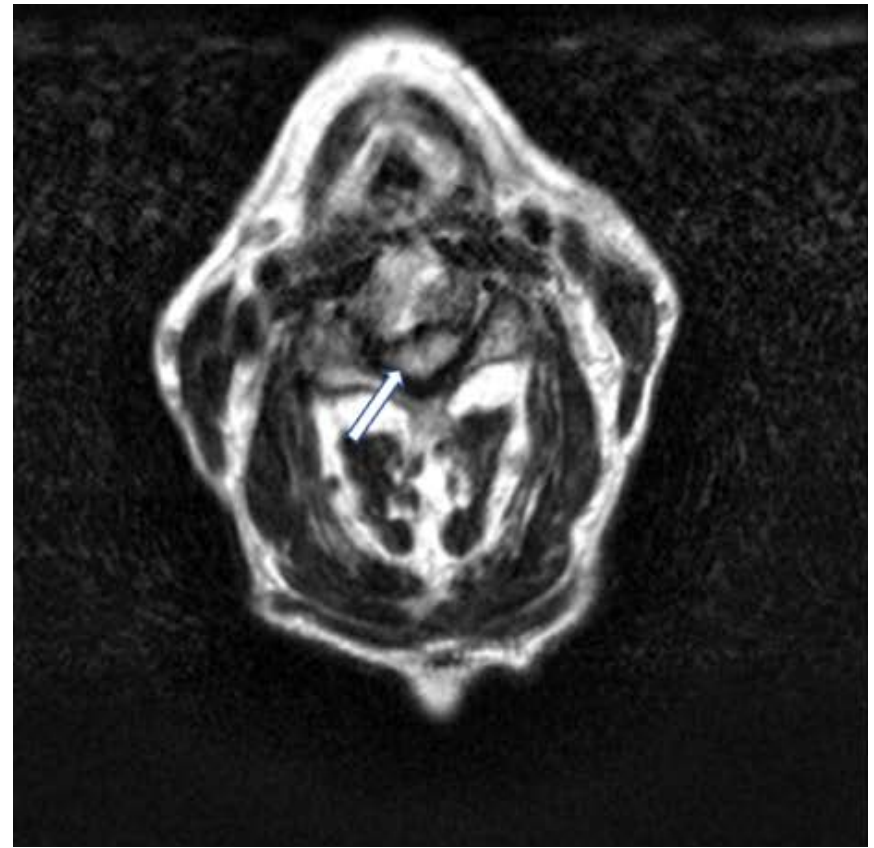

B

Figure 1: (A) MRI, sagittal T2-weighted image of the cervical spine demonstrating spinal canal narrowing due to a large disc osteophyte complex between C5 and C6 (white arrow). Note a subtle retrolisthesis of C5 on C6 and anterolisthesis of C7 on T1; (B) MRI, axial T2-weighted imaging of the cervical spine at the level of C4-5 showing a circumferential absence of cerebrospinal fluid signal and a kidney bean-shaped deformation of the cord (white arrow) [1].

lar tracts (sensory information from limbs and trunk to the cerebellum for movement control) have the most damage [9]. Thus, a broad-based spastic gait and numb clumsy hands are often seen [9]. Other upper motor neuron findings include a positive Hoffman sign, Babinski and/or Chaddock reflex, or an increased deep tendon reflex. Lower motor neuron findings include motor weakness, muscle atrophy, or hypoactive reflexes. Additionally, individuals may have a coexisting radiculopathy (ie, myeloradiculopathy) in which patients complain of neck and shoulder pain associated with the correlating cervical dermatomes due to concomitant nerve root compression.

\section{Diagnosis}

\section{Diagnostic testing}

Imaging techniques to assist with CSM include radiographs (AP and lateral), CT, and MRI. Radiographs can provide information regarding disk space collapse, osteophyte formation, bony end-plate sclerosis, or spondylolisthesis. CT is useful in evaluating the osseous anatomy such as facet hypertrophy, ossification of the posterior longitudinal ligament, or assessing arthrodesis in patients with prior surgery. CT myelography incorporates an intrathecal contrast to evaluate bony abnormalities and regions of spinal cord compression. CT myelography is the test of choice in patients with a contraindication to MRI [5]. MRI is considered the most useful test because it can document the extent of the spinal cord compression, evaluate soft tissue abnormal- ities, assess the severity of the degenerative changes (eg, disk-osteophyte complex, ligamentous hypertrophy), and assist with preoperative planning (Figure $1 \mathrm{~A}$ and Figure $1 \mathrm{~B}$ ). All three imaging modalities can be used to measure the diameters of the cervical spinal canal. Normal adult AP diameter of the canal is $17 \mathrm{~mm}$ to 18 $\mathrm{mm}$, and anything less than $10 \mathrm{~mm}$ is considered absolute cervical spinal stenosis [10].

\section{Equivocal or negative CSM diagnosis}

In the event that imaging does not yield conclusive evidence for a CSM diagnosis, it is important to have several differential diagnoses that can mimic myelopathy. Such alternative diagnoses can include vascular (eg, arteriovenous malformation, brain stem stroke), infection (eg, Lyme disease, abscess), inflammatory (eg, multiple sclerosis, lupus, acute transverse myelitis), tumors, trauma, and other conditions (eg, syringomyelia, Guillain-Barré syndrome, amyotrophic lateral sclerosis, vitamin deficiencies). Having a broad differential diagnosis can assist with ancillary testing in the management of suspected CSM patients (Figure 2) [5].

\section{Definitive CSM diagnosis}

Several baseline assessments should be considered in definitive cases of CSM and that includes outcome assessments (pre-op and post-op), cervical alignment parameters, and bone health assessment. Common outcome measures that have been reported include the Japanese orthopaedic association (JOA) score [11], 


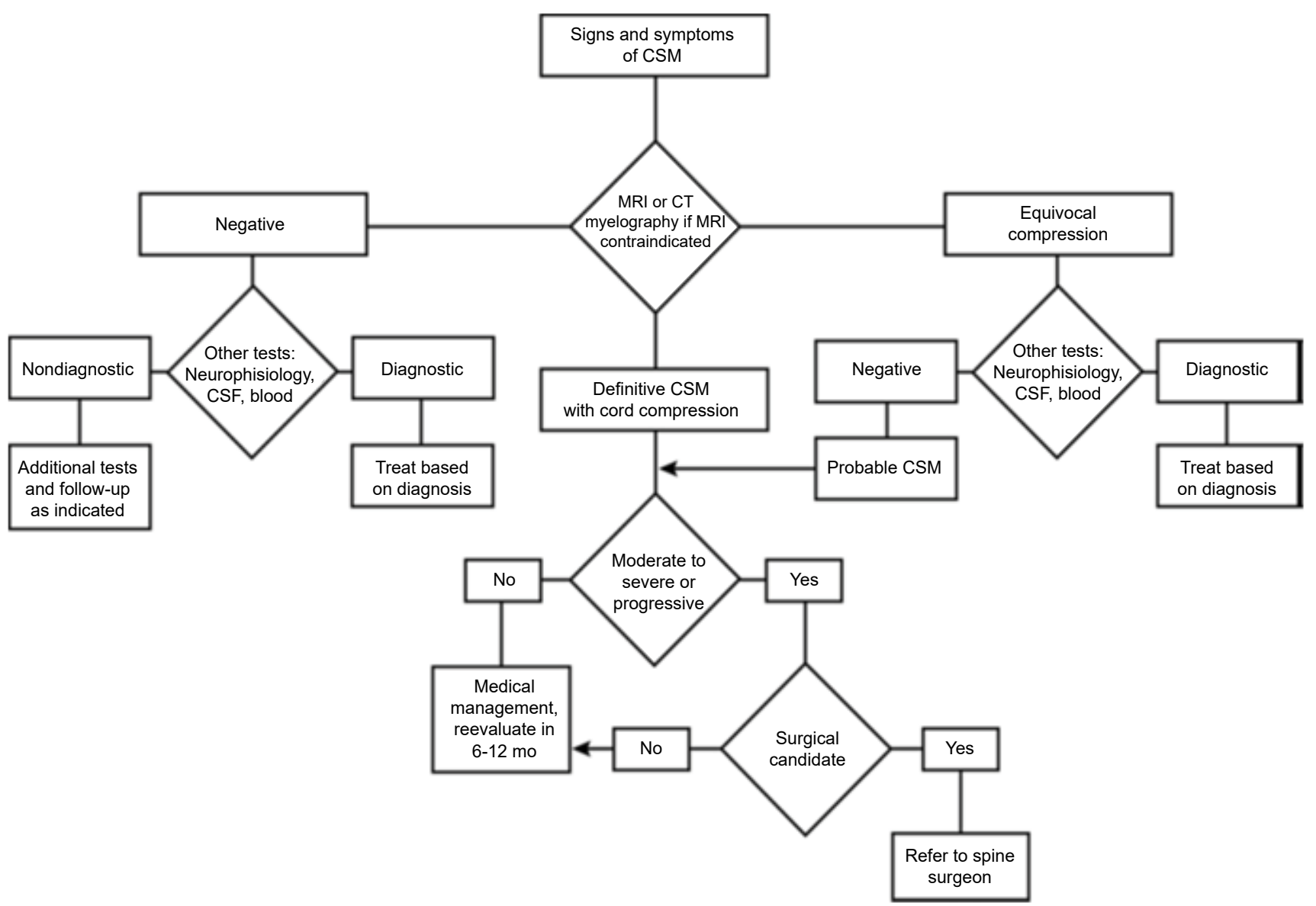

Figure 2: Algorithm summarizing the evaluation and treatment of suspected cervical spondylotic myelopathy [5].

Table 1: Outcome assessment tools used in CSM.

\begin{tabular}{|c|c|c|}
\hline Measurement & Description & Interpretation \\
\hline JOA [11] & $\begin{array}{l}\text { 6 domains: } \\
\text { 1. Motor dysfunction - Upper extremities } \\
\text { 2. Motor dysfunction - Lower extremities } \\
\text { 3. Sensory function - Upper extremities } \\
\text { 4. Sensory function - Lower extremities } \\
\text { 5. Sensory function - Trunk } \\
\text { 6. Bladder function }\end{array}$ & $\begin{array}{l}\text { Total score: } 0-17 \\
\text { Lower score represents greater } \\
\text { disability }\end{array}$ \\
\hline mJOA [11] & $\begin{array}{l}\text { 4 domains: } \\
\text { 1. Motor dysfunction - Upper extremities } \\
\text { 2. Motor dysfunction - Lower extremities } \\
\text { 3. Sensory function - Upper extremities } \\
\text { 4. Bladder function }\end{array}$ & $\begin{array}{l}\text { Total score: } 0-18 \\
\text { Lower score represents greater } \\
\text { disability }\end{array}$ \\
\hline Nurick grade [12] & $\begin{array}{l}\text { Gait impairment assessment } \\
\text { (Grade } 0 \text { - Grade 5) }\end{array}$ & $\begin{array}{l}\text { Higher grade indicates greater } \\
\text { disability (eg, Grade } 5 \text { represents } \\
\text { chair bound or bedridden) }\end{array}$ \\
\hline $\begin{array}{l}\text { Neck disability } \\
\text { index (NDI) [13] }\end{array}$ & $\begin{array}{l}\text { 10 domains assessing neck disability: } \\
\text { 1. Pain intensity higher score indicates greater disability } \\
\text { 2. Personal care } \\
\text { 3. Lifting } \\
\text { 4. Reading } \\
\text { 5. Headaches } \\
\text { 6. Concentration } \\
\text { 7. Work } \\
\text { 8. Driving } \\
\text { 9. Sleeping } \\
\text { 10. Recreation }\end{array}$ & Total score: $0-50$ points \\
\hline
\end{tabular}




\begin{tabular}{|c|c|c|}
\hline $\begin{array}{l}\text { Short-form } 36 \\
\text { Health survey (SF-36) [14] }\end{array}$ & $\begin{array}{l}\text { Health-related quality-of life assessment } \\
8 \text { domains: } \\
\text { 1. Physical functioning } \\
\text { 2. Physical role limitations } \\
\text { 3. Emotional role limitations } \\
\text { 4. Vitality } \\
\text { 5. Social functioning } \\
\text { 6. Pain } \\
\text { 7. Mental health } \\
\text { 8. General health }\end{array}$ & $\begin{array}{l}\text { Total score: } 0-100 \text { points } \\
\text { Lower score indicates greater } \\
\text { disability }\end{array}$ \\
\hline $\begin{array}{l}\text { Visual analogue scale } \\
\text { (VAS) [15] }\end{array}$ & Assessing pain intensity along a continuous line & $\begin{array}{l}\text { One endpoint is no pain while the } \\
\text { other opposite endpoint signifies } \\
\text { the worst pain }\end{array}$ \\
\hline
\end{tabular}

CSM: Cervical spondylotic myelopathy; JOA: Japanese orthopaedic association; mJOA: Modified japanese orthopaedic association.

Modified JOA (mJOA) score [11], Nurick grade [12], Neck disability index (NDI) [13], Short-form 36 health survey (SF-36) [14], and Visual analogue scale (VAS) [15] (Table 1). Although there are more outcome measures than previously described, there is no single outcome instrument to comprehensively assess CSM due to the heterogeneous nature of the disease $[9,16]$. However, it is essential to understand the common outcome measures as most of the literature refer to the different scoring systems, and it helps build a framework for using the measurement tools.

Tan, et al. [17] outlined several radiographic parameters to assess the cervical spine including Cervical lordosis (CL), C2-7 sagittal vertical axis (C2-7 SVA), Chin-brow vertical angle (CBVA), T1 slope (T1S), Thoracic inlet (TIA), and neck tilt. The authors reported that obtaining $\mathrm{T} 1 \mathrm{~A}$, T1S, and neck tilt can help characterize the deformity, but the role in surgical planning and clinical outcomes is questionable. In addition, the authors note that there is a lack of Level 1 evidence that definitively proves the correlation between increased C2-7 SVA and increased disability. However, Ames, et al. [18] reported that C2-7 SVA is correlated to regional disability, general health scores, and to myelopathy severity. Although further investigations are required to assess the relationship between radiographic parameters and outcome measures, obtaining radiographic parameters can serve as a baseline with the ability to track the progress of the patient radiographically.

Bone health assessment is another important factor to consider particularly in the elderly who are commonly afflicted with CSM. Optimizing medical conditions prior to spine surgery is being increasingly performed to improve outcomes, and avert adverse events [19]. Khalid, et al. [20] reported higher rates of postoperative pseudoarthrosis and revision surgery following a single-level lumbar spinal fusion in patients with osteopenia and osteoporosis compared to patients with normal Bone mineral densities (BMD). The authors note that pretreatment with medications to prevent bone loss prior to surgery decreased complication rates. Yan, et al. [21] reported a greater degree of cage subsidence rates in patients with severe osteoporosis treated with anterior corpectomy and titanium mesh cages. Further investigations are required to determine the benefit of taking preventive bone loss medications for cervical spinal surgery, but high-risk patients with poor bone health may warrant a baseline BMD evaluation.

\section{Surgical Approaches and Outcomes}

\section{Anterior techniques}

Anterior techniques are well suited to treat ventral pathology when cervical kyphosis is present, restore cervical lordosis, and permits adequate decompression of the spinal cord for central and posterolateral disk herniations [4]. At risk structures unique to the anterior approach include the esophagus, trachea, carotid vasculature, and recurrent laryngeal nerve which can result in complications including injury to the esophagus or trachea, vascular injury, or vocal cord paralysis, respectively [22].

\section{Anterior cervical discectomy and fusion (ACDF)}

ACDF is a common procedure to treat 1-level to 2-level disease by removing the disk material and fusing the disk space with an interbody graft. Gillis, et al. [23] reported that with a 1-level to 2-level ACDF there was an increase in cervical segmental lordosis of $6.45^{\circ}$ at a 1 year follow up. The authors also noted a mean improvement of $3.46^{\circ}$ in overall C2-7 cervical lordosis by 1 year. However, ACDF is not commonly performed in multilevel (>3-levels) disease because a greater theoretic risk of pseudoarthrosis due to more graft-host interfaces $[7,22]$.

\section{Corpectomy}

Cervical corpectomy is a procedure that removes the vertebral body and the cervical disks above and below the involved vertebral body. Corpectomy is used in the setting of significant retrovertebral disease, ossification of the posterior longitudinal ligament, or if the structural integrity of the vertebral body is comprised 
secondary to pathology $[22,24]$. Complications associated with corpectomies include graft migration, graft dislodgment, and graft subsidence $[7,22]$. Sarkar, et al. [25] reported the most frequent complication following a central corpectomy using autologous iliac crest or fibular strut grafting was a dural tear $(4.3 \%)$ followed by surgical-site infection (3.4\%), C-5 palsy, (1.3\%), dysphagia $(0.8 \%)$, and recurrent laryngeal nerve injury (0.4\%). Vedantam, et al. [26] reported that the prevalence of Clinical adjacent-segment pathology (CASP) following central corpectomy for CSM was 3.9\%. Tan, et al. [24] noted that there can be a high instrumentation failure rate of up to $50 \%$ to $71.4 \%$ when multiple level corpectomies (> 2 levels) are performed [24,27,28]. Therefore, supplemental posterior fixation is recommended when greater than 3 levels are performed [24,29]. In comparing ACDF with Anterior cervical corpectomy and fusion (ACCF) for a two-level adjacent CSM, Liu, et al. [30] reported that both procedures had high fusion rates and improved neurological function, but ACDF was found to have less operation duration, less blood loss, and better cervical lordosis.

\section{Hybrid decompression}

Hybrid decompression composing of 1-level corpectomy plus 1-level discectomy has been performed for multilevel CSM. Several studies have looked at the comparison between ACDF and hybrid procedures. $\mathrm{Xu}$, et al. [31] looked at patients $(n=82)$ with 3-level CSM who underwent ACDF $(n=40)$ and hybrid decompression ( $n$ $=42$ ), and were followed up for a mean of 35.5 months. The authors noted similar improvements in the NDI and JOA scores in both procedures, but ACDF demonstrated superiority to hybrid decompression in terms of less blood loss, shorter operation time, and better postoperative sagittal balance. The ACDF group had greater restoration of segmental and $C 2-7$ lordosis $(P<0.05)$, and a significantly reduced T1 slope minus $\mathrm{C} 2-7$ lordosis $(P<0.05)$. Badhiwala, et al. [32] compared the outcomes from 3-level ACDF $(n=713)$, 2-level ACCF $(n=$ $314)$, and hybrid decompression $(n=271)$ from a large North American administrative healthcare database (Table 2). The study cohort consisted of 1298 patients, and the authors concluded that 2-level ACCF had more major complications (5.7\%), longer hospital stays, and

Table 2: Major outcomes of the cervical surgical approaches from anterior to posterior to anterior-posterior.

\begin{tabular}{|c|c|c|c|c|}
\hline Authors & Study design & No. Patients & Procedures & Significant Outcomes \\
\hline $\begin{array}{l}\text { Badhiwala, et al. } \\
\text { [32] }\end{array}$ & $\begin{array}{l}\text { Retrospective } \\
\text { database }^{a}\end{array}$ & $N=1298$ & $\begin{array}{l}\text { 3-level ACDF, } \\
\text { hybrid corpectomy, } \\
\text { major complication } \\
\text { compared to a 3-level } \\
\text { ACDF, (aOR 2.82, p } \\
=0.005)\end{array}$ & $\begin{array}{l}\text {-Among all } 3 \text { procedures, no difference in } 30 \text {-day } \\
\text { or mortality rate, reoperation, or readmission } \\
\text {-Level ACCF was associated with a higher risk of } \\
\text { discectomy } \\
\text {-Multiple discectomies and hybrid procedures had } \\
\text { comparable safety profiles } \\
\text {-Multiple corpectomies associated with higher } \\
\text { complications and longer hospital stay }\end{array}$ \\
\hline $\begin{array}{l}\text { Lee } \mathrm{CH} \text {, et al. } \\
\text { [38] }\end{array}$ & $\begin{array}{l}\text { Meta-analysis } \\
\text { (7 studies) }\end{array}$ & $N=592$ & $\begin{array}{l}\text { Laminoplasty, or } \\
\text { LPSP }\end{array}$ & $\begin{array}{l}\text {-No superiority over one approach laminoplasty, } \\
\text { or laminectomy + on JOA grade and VAS score } \\
\text { fusion. } \\
\text {-Even loss of cervical lordosis in both groups } \\
\text {-Pain outcomes were similar between both groups } \\
\text { in patients with similar post-op cervical lordosis } \\
\text { and sagittal alignment } \\
\text {-Better pain outcomes in laminoplasty pts. With } \\
\text { greater cervical lordosis }\left(>20^{\circ}\right) \\
\text {-LPSP associated with higher long-term } \\
\text { complication rate, but better neurological outcomes } \\
\text { compared to laminoplasty }\end{array}$ \\
\hline $\begin{array}{l}\text { Wewel JT, et al. } \\
\text { [53] }\end{array}$ & Retrospective & $N=72$ & $\begin{array}{l}\text { Single stage } \\
\text { anterior- posterior- or } \\
\text { posterior-anterior- } \\
\text { posterior }\end{array}$ & $\begin{array}{l}\text { Within } 90 \text { days following surgery: } \\
-30.6 \% \text { major complications (eg, death, stroke) } \\
-80.6 \% \text { minor complications (eg, PE, dysphagia) } \\
-13.9 \% \text { reoperation rate }\end{array}$ \\
\hline $\begin{array}{l}\text { Veeravagu, et al. } \\
\text { [51] }\end{array}$ & Retrospective & $N=35,962$ & $\begin{array}{l}\text { ACDF, posterior } \\
\text { fusion, laminoplasty, } \\
\text { anterior- posterior }\end{array}$ & $\begin{array}{l}\text { Within } 30 \text { days after surgical discharge date } \\
\text {-ACDF, posterior fusion, laminoplasty, and } \\
\text { anterior- posterior had complication rates of } 15.6 \% \text {, } \\
29.2 \%, 22.4 \%, 41.1 \% \text {, respectively } \\
\text {-Dysphagia rate of } 4.1 \%, 1.6 \%, 0.35 \% \text {, and } 11.3 \% \\
\text { for ACDF, posterior fusion, laminoplasty, and } \\
\text { anterior-posterior, respectively }\end{array}$ \\
\hline
\end{tabular}




\begin{tabular}{|c|c|c|c|c|}
\hline $\begin{array}{l}\text { Fehlings MG, et } \\
\text { al. [50] }\end{array}$ & & $N=302$ & $\begin{array}{l}\text { Anterior-only, } \\
\text { posterior-only, or } \\
\text { anterior-posterior }\end{array}$ & $\begin{array}{l}\text {-Anterior-only, posterior-only, and } 2 \text {-stage anterior- } \\
\text { posterior had complication rates of } 11 \%, 19 \% \text {, and } \\
37 \% \text {, respectively } \\
\text {-Dysphagia rate of } 2.3 \%, 0.9 \% \text {, and } 21.1 \% \text { for } \\
\text { anterior-only, posterior-only, and combined } \\
\text { approach, respectively }\end{array}$ \\
\hline $\begin{array}{l}\text { Smith JS, et al. } \\
\text { [52] }\end{array}$ & $\begin{array}{l}\text { Prospective } \\
\text { multicenter }\end{array}$ & $\begin{array}{l}\text { Prospective } \\
\text { multicenter } \\
\mathrm{N}=78\end{array}$ & $\begin{array}{l}\text { Anterior-only, } \\
\text { posterior-only, or } \\
\text { anterior-posterior }\end{array}$ & $\begin{array}{l}\text {-Anterior-only, posterior-only, and anterior- } \\
\text { posterior had early complication rates of } 27.3 \% \text {, } \\
\text {-Dysphagia rate of } 8.1 \%, 2.6 \% \text {, and } 24.1 \% \text { for } \\
\text { anterior-only, posterior-only, and combined } \\
\text { approach, respectively }\end{array}$ \\
\hline
\end{tabular}

a: Database was acquired from the national surgical quality improvement program (NSQIP) of the American college of surgeons (ACS); ACDF: Anterior cervical discectomy and fusion; ACCF: Anterior cervical corpectomy and fusion; aOR: Adjusted odds ratio; JOA: Japanese orthopaedic association; VAS: Visual analog scale; LPSP: Laminectomy with posterior spinal fusion; post-op: Post-operative; pts: Patients; PE: Pulmonary embolism.

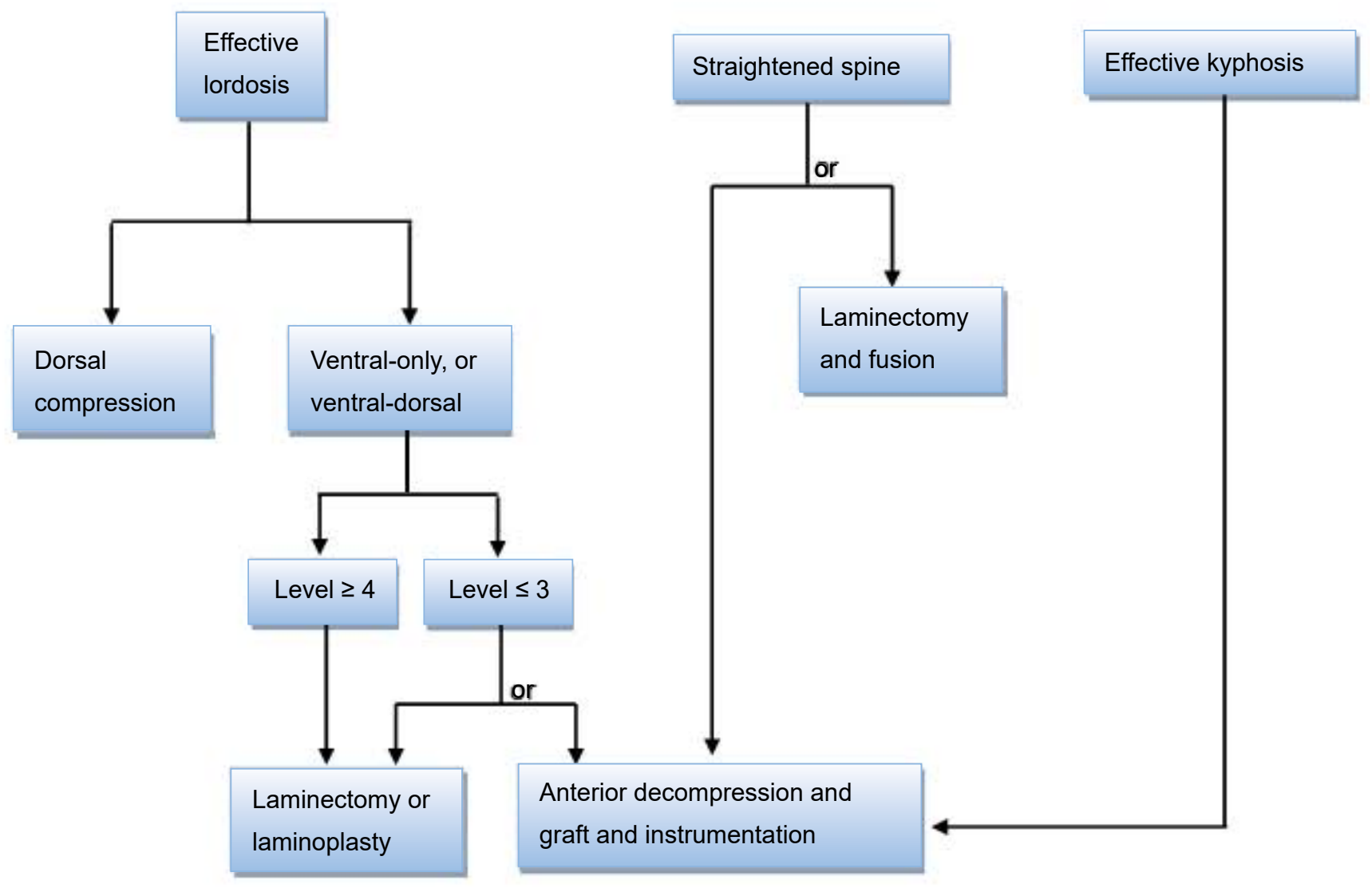

Figure 3: Surgical treatment algorithm for cervical spondylotic myelopathy [4].

lower likelihood of being discharged from the hospital. However, 3-level ACDF and hybrid decompression had similar major complication rates of $2.0 \%$ and $1.9 \%$, respectively.

\section{Posterior techniques}

Posterior techniques have been well suited for patients with multilevel CSM, preservation of cervical lordosis, and ankylosed spines [33-37]. Given the complication rates and technically demanding operations associated with anterior approaches for multilevel CSM, posterior approaches are commonly performed [3840]. However, controversy exists on the optimal surgical approach (ie, anterior-only, posterior-only, or ante- rior-posterior) and there are a multitude of factors to consider such as the number of levels of compression, location and type of pathology, clinical factors (eg, neck pain, motor and sensory components), presence of instability, presence of OPLL, and radiological factors (eg, sagittal alignment). Yet, a good general approach was described by Meyer and Knightly [4] in Figure 3.

The concept of posterior approaches is to indirectly decompress the spinal cord by a "drift back" of the cord away from anterior pathology [41]. Therefore, the sagittal alignment of the cervical spine becomes important because a kyphotic cervical spine hinders the migration posteriorly, and worsening neurological function can ensue if kyphosis progresses. A kyphosis greater than 
$13^{\circ}$ has been associated with unfavorable outcomes following a posterior-only approach for CSM [41,42].

Laminectomy and fusion have largely replaced stand alone laminectomy because of the concern for segmental instability and postlaminectomy kyphosis which can occur in $10 \%$ to $45 \%$ of patients following laminectomy-only procedures $[33,43]$. Laminectomy with fusion can stabilize the spine, thereby providing pain relief but there is significant alteration of the natural biomechanics of the cervical spine. However, laminoplasty is a motion-sparing technique that can widen the spinal canal typically at the lateral mass-laminar junction. No fusion is required and therefore the procedure can avoid certain complications (eg, pseudoarthrosis, ASD) while maintaining some degree of motion. There is still some debate over which procedure is superior to the other [38,44-48]. Lee, et al. [38] performed a meta-analysis on the outcomes between the two posterior approaches (Table 2). Both groups had similar improved JOA and neck pain VAS scores. In addition, both groups evenly lost cervical lordosis, but at an 18-month minimum follow-up the laminectomy plus fusion group continued to preserve cervical lordosis. The authors could not conclude on the superiority of one procedure over the other. Similarly, Lau, et al. [49] compared the outcomes of the two posterior approaches with a mean follow up of 17.3 months (Table 2). The authors reported that there was a significant association between neck pain VAS scores and cervical sagittal Cobb angle. Patients with greater cervical lordosis correlated with lower VAS scores and this trend was seen in laminoplasty patients, but not in the laminectomy plus fusion group.

\section{Combined approach}

Combined (circumferential) approaches include posterior-anterior-posterior or anterior-posterior that can be performed in a single-stage or two-stage procedure. Sometimes a combined approach is necessary to provide adequate decompression because some patients have greater disease pathology. Fehlings, et al. [50] reported that most individuals with CSM who required a combined approach had greater cervical disease at baseline (i.e, lower mJOA scores), and had greater number of spinal levels to operate than for a single-approach. Veeravagu, et al. [51] Fehlings, et al. [50] and Smith, et al. [52] reported high complication rates for a combined approach compared to a single-approach (Table 2). However, it should be noted that although Smith, et al. [52] reported a high complication rate (79.3\%), the study did not include CSM as a diagnostic category but rather adult cervical deformities. In addition, the study included osteotomies in the surgical procedures. Wewel, et al. [53] reported a major complication rate of $30.6 \%$ for a single-stage anterior-posterior or posterior-anterior-posterior decompression and fusion (Table 2 ). In addition, the highest minor complication was identified as dysphagia (62.5\%). This trend of high dysphagia rate in combined approaches was also seen in Fehlings, Veeravagu, and Smith report (Table 2). Smith offered an explanation that the high dysphagia rate may be due to greater operative times and greater magnitude of the combined approach (i.e, more spine levels, greater realignment). It appears that the timing of the procedure (1-stage vs. 2-stage) makes no difference in the rate of dysphagia since Smith and Wewel reported a single-stage combined approach, but Fehlings accounted for a 2-stage combined procedure. Although the overall complication rate is higher for the combined approach, the complication may be related to the severity of the CSM pathology and the use of the combined approach should not be discouraged since these approaches can best address the disease pathology [52].

\section{Outcomes in the Elderly}

The elderly is a fast-growing population in the U.S. and as the lifespan has lengthened, CSM is expected to increase in the elderly [54]. Surgical outcomes in the elderly have reported mixed results [54-57]. However, two large-scale studies provide some insight in elderly outcomes. Madhavan, et al. [58] performed a meta-analysis in the surgical outcomes in the elderly with CSM with a mean follow-up between 24 to 78 months (Table 3). The analysis looked at 18 studies comprising the elderly ( $n=1169$ ) and nonelderly $(n=1699)$ that underwent anterior and posterior procedures. Significant outcomes were noted in blood loss $(P=0.03)$, JOA scores $(P<0.00001)$, recovery rate $(P<0.00001)$, length of stay $(P<0.00001)$, and Cobb angle $(P=0.007)$. There were no significant differences in C-5 palsy, CSF leak, or pneumonia, but delirium was significantly higher in the elderly $(P=0.04)$. Veeravagu, et al. [51] performed a retrospective study using the Market Scan database comprising the elderly ( $n=5154$ ) and nonelderly ( $n=$ $30,808)$ who underwent ACDF, posterior fusion, anterior-posterior, or laminoplasty (Tables 2 and Table 3). The elderly had significantly more complications following ACDF $(P<0.0001)$ and posterior fusion $(P=0.0084)$ compared to the nonelderly. In addition, the elderly had lower 30-day readmission rates in all 4 surgical cohorts compared to the nonelderly.

\section{Cost-Utility Analysis}

A metric to determine the cost-effectiveness of an intervention is termed quality-adjusted life year (QALY). QALY is an outcome measure that takes into account the duration (quantity) and quality of a patient's life. QALY is measured on a scale from 0 to 1 , where 0 indicates death and 1 indicates the best possible health outcome [59]. For example, if a patient with CSM has 0.55 QALY, then 1 year of life with CSM is equivalent to 0.55 years in perfect health. If the patient underwent spine surgery and then had a QALY of 0.75, the annual gain is 0.2 QALYs. In Table 4, Carreon, et al. [60] reported 0.88 QALY gain over 5 years for an ACDF. Witiw, et al. [61] reported 
Table 3: Two large scale comparative analysis on the outcomes in elderly with CSM.

Outcomes Madhavan, et al. [58] ( $N=2868)$ Veeravagu, et al. [51] $(N=35,962)$

Operative time Similar operative times between elderly and nonelderly groups

Blood loss Elderly had less blood loss compared to nonelderly

JOA scores Elderly had lower pre-op and post-op scores compared to nonelderly

Recovery rates Elderly had lower recovery rates

LOS in hospital Elderly had longer LOS

Cervical Cobb angle

Spinal canal diameter Elderly had smaller pre-post-op Cobb angles compared to nonelderly Elderly had greater post-op diameter

Complication rates

No significant difference between Significantly higher elderly and nonelderly complication rates in the elderly compared to nonelderly following ACDF and posterior fusion

30-day readmission rates

Lower readmission rates in the elderly compared to nonelderly

CSM: Cervical spondylotic myelopathy; JOA: Japanese orthopaedic association; Pre-op: Pre-operative; Post-op: Post-operative; LOS: length of stay ; ACDF = Anterior cervical discectomy and fusion.

Table 4: Cost-effectiveness of cervical surgery.

\begin{tabular}{|c|c|c|c|c|c|}
\hline Authors & Study design & $\begin{array}{l}\text { No. Patients/ } \\
\text { Age }(y)\end{array}$ & Procedures & Follow Up & Outcomes \\
\hline Carreon, et al. [60] & Longitudinal cohort & $\begin{array}{l}N=352 A C D F \\
\text { Mean- } \\
44.6(\text { Single } \\
\text { level) }\end{array}$ & & 5 years & $\begin{array}{l}-1 \text { year- } \$ 104,831 / \mathrm{QALY} \\
-2 \text { years- } \$ 53,074 / \mathrm{QALY} \\
-3 \text { years- } \$ 37,717 / \mathrm{QALY} \\
-4 \text { years- } \$ 28,383 / \mathrm{QALY} \\
-5 \text { years- } \$ 23,460 / \mathrm{QALY} \\
-0.88 \text { QALY gain over } 5 \text { years }\end{array}$ \\
\hline Witiw, et al. [61] & $\begin{array}{l}\text { Prospective } \\
\text { observational } \\
\text { cohort }\end{array}$ & $\begin{array}{l}N=171 \\
\text { Mean-58.2 }\end{array}$ & $\begin{array}{l}\text { Anterior-only, } \\
\text { posterior-only, } \\
\text { or combined }\end{array}$ & $\begin{array}{l}\text { months } 6 \\
12,24\end{array}$ & $\begin{array}{l}-0.139 \text { mean QALY gain over } \\
24 \text { months } \\
\text {-Estimated lifetime ICUR for } \\
\text { surgical intervention is } \\
\text { between } \$ 1,496.02 / Q A L Y \text { to } \\
\$ 20,547.84 / Q A L Y\end{array}$ \\
\hline $\begin{array}{l}\text { Whitmore, et al. } \\
\text { [62] }\end{array}$ & $\begin{array}{l}\text { Retrospective cohort } \\
\text { Mean (dorsal)-63.9 }\end{array}$ & $\begin{array}{l}\mathrm{N}=72 \\
\text { Mean } \\
\text { (ventral)-60.5 }\end{array}$ & $\begin{array}{l}\text { Ventral, or } \\
\text { dorsal }\end{array}$ & 1 year & $\begin{array}{l}\text {-0.16 QALY gain in } 1 \text { year with } \\
\text { ventral surgery } \\
-0.13 \text { QALY gain in } 1 \text { year with } \\
\text { dorsal surgery } \\
\text { CCR Method: } \\
\text {-Ventral direct costs- } \$ 21,563 \\
\text {-Dorsal direct costs- } \$ 27,942 \\
(P=0.02) \\
\text { MRM Method: } \\
\text {-Ventral direct costs- } \$ 17,538 \\
\text {-Dorsal direct costs- } \$ 16,579 \\
(P=0.29)\end{array}$ \\
\hline $\begin{array}{l}\text { Fehlings, et al. } \\
\text { [63] }\end{array}$ & $\begin{array}{l}\text { Prospective } \\
\text { multicenter or } \\
\text { combined }\end{array}$ & $\begin{array}{l}N=70 \\
\text { Mean-55.25 }\end{array}$ & $\begin{array}{l}\text { Anterior-only, } \\
\text { posterior-only }\end{array}$ & 1 year & $\begin{array}{l}-0.64 \text { QALY gain over } 10 \\
\text { years } \\
\text {-Mean direct costs- } \$ 21,066 \\
-\$ 32,916 / Q A L Y \text { gain }\end{array}$ \\
\hline $\begin{array}{l}\text { Ghogawala, et al. } \\
\text { [64] }\end{array}$ & $\begin{array}{l}\text { Prospective pilot } \\
\text { study }\end{array}$ & $\begin{array}{l}\mathrm{N}=50 \text { ventral, } \\
\text { or Mean-61.6 } \\
\text { dorsal }\end{array}$ & & 1 year & $\begin{array}{l}\text {-Ventral mean costs- } \$ 19,245 \\
\text {-Dorsal mean costs- } \$ 29,465\end{array}$ \\
\hline
\end{tabular}

Y: Years; ACDF: Anterior cervical discectomy and fusion; QALY: Quality-adjusted life year; ICUR: Incremental cost-to-utility ratio; CCR: Cost-to-charge ratio; MRM: Medicare reimbursement method. 
0.139 QALY gain over 2 years for all surgical approaches. Whitmore, et al. [62] accounted 0.16 QALY gain for ventral surgery and 0.13 QALY gain for dorsal surgery in a 1-year period. Fehlings, et al. [63] stated a 10-year QALY gain of 0.64 for all surgical approaches.

The metric to determine the value of the intervention is the cost per QALY (cost/QALY) gained [60]. Interventions considered cost-effective are between $\$ 50,000 / Q A L Y$ to $\$ 100,000 / Q A L Y$, or a cost/QALY gained less than the country's per capita gross domestic product [60]. Carreon, et al. [60] reported an incremental decrease in cost/QALY over 5 years demonstrating the cost-effectiveness of ACDF (Table 4). In all surgical approaches combined, Witiw, et al. [61] calculated the cost/QALY using two models and arrived at $\$ 11,496.02 /$ QALY gained to $\$ 20,547.84 /$ QALY gained (Table 4). Thus, demonstrating the cost-effectiveness of spine surgery for CSM. Similarly, Fehlings, et al. [63] cited the cost-effectiveness of all surgical procedures combined with a cost/QALY of $\$ 32,916 /$ QALY gained.

In comparing the cost-effectiveness between ventral and dorsal surgery, there appears to be a greater benefit with the ventral approach (Table 4). Ghogawala, et al. [64] and Whitmore, et al. [62] reported lower mean ventral costs compared to dorsal surgery. Whitmore, et al. [62] cited a slightly higher ventral QALY gain compared to dorsal surgery. In addition, Carreon, et al. [60] displayed a high QALY gain in 5 years and a low sequential drop in cost/QALY over 5 years for the anterior approach.

\section{Future Directions}

Prospective randomized evidence is needed to determine the optimal surgical approach for single-level and multilevel CSM. A large number of retrospective studies were used in the meta-analysis in this review. The paucity of randomized prospective studies will hopefully encourage more studies in the future. Clinical trials do reveal a beacon of hope as more investigators are comparing ventral and dorsal surgery for CSM (NCT00506558, NCT00565734, NCT00285337, NCT02076113, NCT00876603).

Additional work is being done to look at neuroprotective agents. Riluzole is a sodium and glutamate-blocking medication that is FDA-approved to treat Amyotrophic lateral sclerosis (ALS). Preclinical studies suggest that glutamate-related excitotoxicity contributes to CSM pathology [65]. A completed Phase 3 trial (NCT01257828) evaluated the efficacy of riluzole in CSM patients undergoing surgical decompression. Medications that are approved for one condition may find themselves being used for other conditions such as riluzole.

The emerging area of nanotechnology has made its way into spine surgery. Currently, silicon nitride $\left(\mathrm{Si}_{3} \mathrm{~N}_{4}\right)$ ceramic nanoparticles are being used in cages for cervical spine $[66,67]$. The ceramic material has a hydrophilic negative charge which facilitates bone remodeling, and thus avoiding co-morbidities associated with harvesting bone autograft [66]. Arts, et al. [67] compared Polyetheretherketone (PEEK) and silicon nitride cages for ACDF and found similar clinical outcomes. It seems likely that other nanoscaffolds will continue to emerge and be used in spinal implants to improve patient outcomes.

\section{Disclosures}

The author reports no conflict of interest concerning the materials or methods used in this study or the findings specified in this paper.

\section{Disclosures of Funding}

None.

\section{References}

1. Amenta PS, Ghobrial GM, Krespan K, Nguyen P, Ali M, et al. (2014) Cervical spondylotic myelopathy in the young adult: A review of the literature and clinical diagnostic criteria in an uncommon demographic. Clin Neurol Neurosurg 120: 68-72.

2. Theodore $N(2020)$ Degenerative cervical spondylosis. $N$ Engl J Med 383: 159-168.

3. Wu JC, Ko CC, Yen YS, Huang WC, Chen YC, et al. (2013) Epidemiology of cervical spondylotic myelopathy and its risk of causing spinal cord injury: A national cohort study. Neurosurg Focus.

4. Meyer SA, Knightly JJ (2017) Evaluation and treatment of cervical disk herniations. In: Youmans, Winn, Neurological Surgery. ( $7^{\text {th }}$ edn), Elsevier, Philadelphia.

5. Toledano M, Bartleson JD (2013) Cervical spondylotic myelopathy. Neurol Clin 31: 287-305.

6. Karadimas SK, Erwin WM, Ely CG, Dettori JR, Fehlings MG (2013) Pathophysiology and natural history of cervical spondylotic myelopathy. Spine 38: S21-S36.

7. Iyer A, Azad TD, Tharin S (2016) Cervical spondylotic myelopathy. Clin Spine Surg 29: 408-414.

8. Tracy JA, Bartleson JD (2010) Cervical spondylotic myelopathy. The Neurologist 16: 176-187.

9. Singh A, Tetreault L, Casey A, Laing $R$, Statham $P$, et al. (2015) A summary of assessment tools for patients suffering from cervical spondylotic myelopathy: A systematic review on validity, reliability, and responsiveness. Eur Spine J 24: S209-S228.

10. Lund T, Santos de Moraes JS (2017) Cervical, Thoracic, and Lumbar Stenosis. In: Youmans, Winn, Neurological Surgery. ( $7^{\text {th }}$ edn), Elsevier, Philadelphia.

11. Kato S, Oshima $Y$, Oka H, Chikuda H, Takeshita $Y$, et al. (2015) Comparison of the japanese orthopaedic association (JOA) score and modified JOA (mJOA) score for the assessment of cervical myelopathy: A multicenter observational study. PLoS One.

12. Revanappa KK, Rajshekhar V (2011) Comparison of nurick grading system and modified japanese orthopaedic association scoring system in evaluation of patients with cervical spondylotic myelopathy. Eur Spin J 20: 1545-1551.

13. Vernon $H$ (2008) The neck disability index: State-of-the-art, 1991-2008. J Manipulative Physiol Ther 31: 491-502.

14. Brazier JE, Harper R, Jones NMB, O'Cathain A, Thomas KJ, et al. (1992) Validating the SF-36 health survey ques- 
tionnaire: New outcome measure for primary care. Brit Med J 305: 160-164.

15. Reed MD, Van Nostran W (2014) Assessing pain intensity with the visual analog scale: A plea for uniformity. J Clin Pharmacol 54: 241-244.

16. Kalsi-Ryan S, Karadimas SK, Fehlings MG (2013) Cervical spondylotic myelopathy: The clinical phenomenon and the current pathobiology of an increasingly prevalent and devastating disorder. Neuroscientist 19: 409-421.

17. Tan LA, Riew KD, Traynelis VC (2017) Cervical spine deformity-Part 1: Biomechanics, radiographic parameters, and classification. Neurosurgery 81: 197-203.

18. Ames CP, Blondel B, Scheer JK, Schwab FJ, Le Huec JC, et al. (2013) Cervical radiographical alignment: Comprehensive assessment techniques and potential importance in cervical myelopathy. Spine 38: S149-S160.

19. Anderson PA, Kadri A, Hare KJ, Binkley N (2020) Preoperative bone health assessment and optimization in spine surgery. Neurosurg Focus.

20. Khalid SI, Nunna RS, Maasarani S, Belmont E, Deme P, et al. (2020) Association of osteopenia and osteoporosis with higher rates of pseudoarthrosis and revision surgery in adult patients undergoing single-level lumbar fusion. Neurosurg Focus.

21. Yan D, Wang Z, Deng S, Li J, Soo C (2011) Anterior corpectomy and reconstruction with titanium mesh cage and dynamic cervical plate for cervical spondylotic myelopathy in elderly osteoporosis patients. Arch Orthop Trauma Surg 131: 1369-1374.

22. Siemionow KB, Neckrysh S (2012) Anterior approach for complex cervical spondylotic myelopathy. Orthop Clin N Am 43: 41-52.

23. Gillis CC, Kaszuba MC, Traynelis VC (2016) Cervical radiographic parameters in 1- and 2-level anterior cervical discectomy and fusion. J Neurosurg Spine 25: 421-429.

24. Tan LA, Riew KD, Traynelis VC (2017) Cervical Spine Deformity-Part 2: Management algorithm and anterior techniques. Neurosurgery 81: 561-567.

25. Sarkar S, Nair BR, Rajshekhar V (2016) Complications following central corpectomy in 468 consecutive patients with degenerative cervical spine disease. Neurosurg Focus 40 E10.

26. Vedantam A, Rajshekhar V (2016) Clinical adjacent-segment pathology after central corpectomy for cervical spondylotic myelopathy: Incidence and risk factors. Neurosurg Focus.

27. Sasso RC, Ruggiero RA, Reilly TM, Hall PV (2003) Early reconstruction failures after multilevel cervical corpectomy. Spine 25: 140-142.

28. Vaccaro AR, Falatyn SP, Scuderi GJ, Eismont FJ, McGuire RA, et al. (1998) Early failure of long segment anterior cervical plate fixation. J Spinal Disord 11: 410-415.

29. Gok B, Sciubba DM, McLoughlin GS, McGirt M, Ayhan S, et al. (2008) Surgical treatment of cervical spondylotic myelopathy with anterior compression: A review of 67 cases. J Neurosurg Spine 9: 152-157.

30. Liu J, Chen X, Liu Z, Long X, Huang S, et al. (2015) Anterior cervical discectomy and fusion versus corpectomy and fusion in treating two-level adjacent cervical spondylotic myelopathy: A minimum 5-year follow-up study. Arch Orthop Trauma Surg 135: 149-153.
31. Xu Z, Rao H, Zhang L, Li G, Xu Z, et al. (2019) Anterior cervical discectomy and fusion versus hybrid decompression and fusion for the treatment of 3-level cervical spondylotic myelopathy: A comparative analysis of cervical sagittal balance and outcomes. World Neurosurg.

32. Badhiwala JH, Leung SN, Ellenbogen Y, Akbar MA, Martin $A R$, et al. (2020) A comparison of the perioperative outcomes of anterior surgical techniques for the treatment of multilevel degenerative cervical myelopathy. J Neurosurg Spine.

33. Kiely PD, Quinn JC, Du JY, Lebl DR (2015) Posterior surgical treatment of cervical spondylotic myelopathy. HSS J.

34. Geck MJ, Eismont FJ (2002) Surgical options for the treatment of cervical spondylotic myelopathy. Orthop Clin North Am 33: 329-348.

35. Hukuda S, Mochizuki T, Ogata M, Shichikawa K, Shimomura $Y$ (1985) Operations for cervical spondylotic myelopathy. A comparison of the results of anterior and posterior procedures. J Bone Joint Surg Br 67: 609-615.

36. Menezes AH (2008) Decision making. Childs Nerv Syst 24: 1147-1153.

37. Lawrence BD, Brodke DS (2012) Posterior surgery for cervical myelopathy: Indications, techniques, and outcomes. Orthop Clin N Am 43: 29-40.

38. Lee CH, Lee J, Kang JD, Hyun SJ, Kim KJ, et al. (2015) Laminoplasty versus laminectomy and fusion for multilevel cervical myelopathy: A meta-analysis of clinical and radiological outcomes. J Neurosurg Spine 22: 589-595.

39. Lin X, Cai J, Qin C, Yang Q, Xiao Z (2019) Comparison of clinical outcomes and safety between laminectomy with instrumented fusion versus laminoplasty for the treatment of multilevel cervical spondylotic myelopathy. Medicine.

40. Rhee JM, Basra S (2007) Posterior surgery for cervical myelopathy: Laminectomy, laminectomy with fusion, and laminoplasty. Asian Spine J 2: 114-126.

41. Lebl DR, Bono CM (2015) Update on the diagnosis and management of cervical spondylotic myelopathy. J Am Acad Orthop Surg 23: 648-660.

42. Suda K, Abumi K, Ito M, Shono Y, Kaneda K, et al. (2003) Local kyphosis reduces surgical outcomes of expansive open-door laminoplasty for cervical spondylotic myelopathy. Spine 28: 1258-1262.

43. Kato Y, Iwasaki M, Fuji T, Yonenobu K, Ochi T (1998) Long-term follow-up results of laminectomy for cervical myelopathy caused by ossification of the posterior longitudinal ligament. J Neurosurg 89: 217-223.

44. Hardman J, Graf O, Kouloumberis PE, Gao WH, Chan M, et al. (2010) Clinical and functional outcomes of laminoplasty and laminectomy. Neurol Res 32: 416-420.

45. Highsmith JM, Dhall SS, Haid RW Jr, Rodts GE Jr, Mummaneni PV (2011) Treatment of cervical stenotic myelopathy: A cost and outcome comparison of laminoplasty versus lamninectomy and lateral mass fusion. J Neurosurg Spine 14: 619-625.

46. Manzano GR, Casella G, Wang MY, Vanni S, Levi AD (2012) A prospective, randomized trial comparing expansile cervical laminoplasty and cervical laminectomy and fusion for multilevel cervical myelopathy. Neurosurgery 70 : 264-277.

47. Nurboja B, Kachramanoglou C, Choi D (2012) Cervical laminectomy vs laminoplasty: Is there a difference in outcome and postoperative pain? Neurosurgery 70: 965-970. 
48. Woods BI, Hohl J, Lee J, Donaldson W III, Kang J (2011) Laminoplasty versus laminectomy and fusion for multilevel cervical spondylotic myelopathy. Clin Orthop Relat Res 469: 688-695.

49. Lau D, Winkler EA, Than KD, Chou D, Mummaneni PV (2017) Laminoplasty versus laminectomy with posterior spinal fusion for multilevel cervical spondylotic myelopathy: Influence of cervical alignment on outcomes. J Neurosurg Spine 27: 508-517.

50. Fehlings MG, Smith JS, Kopjar B, Arnold PM, Yoon T, et al. (2012) Perioperative and delayed complications associated with the surgical treatment of cervical spondylotic myelopathy based on 302 patients from the AOSpine north america cervical spondylotic myelopathy study. J Neurosurg Spine 16: 425-432.

51. Veeravagu A, Connolly ID, Lamsam L, Li A, Swinney C, et al. (2016) Surgical outcomes of cervical spondylotic myelopathy: An analysis of a national, administrative, longitudinal database. Neurosurg Focus.

52. Smith JS, Ramchandran S, Lafage V, Shaffrey CI, Ailon T, et al. (2016) Prospective multicenter assessment of early complication rates associated with adult cervical deformity surgery in 78 patients. Neurosurgery 79: 378-388.

53. Wewel JT, Brahimaj BC, Kasliwal MK, Traynelis VC (2020) Perioperative complications with multilevel anterior and posterior cervical decompression and fusion. J Neurosurg Spine.

54. Isogai N, Nagoshi N, Iwanami A, Kono H, Kobayashi $\mathrm{Y}$, et al. (2018) Surgical treatment of cervical spondylotic myelopathy in the elderly: Outcomes in patients aged 80 years or older. Spine.

55. Machino M, Yukawa Y, Hida T, Keigo I, Nakashima H, et al. (2012) Can elderly patients recover adequately after laminoplasty? A comparative study of 520 patients with cervical spondylotic myelopathy. Spine 37: 667-671.

56. Holly LT, Moftakhar P, Khoo LT, Shamie AN, Wang JC (2008) Surgical outcomes of elderly patients with cervical spondylotic myelopathy. Surg Neurol 69: 233-240.

57. Chen J, Liu Z, Zhong G, Qian L, Li Z, et al. (2015) Surgical treatment of cervical myelopathy in elderly patients: A retrospective study. Clin Neurol Neurosurg 132: 47-51.
58. Madhavan K, Chieng LO, Foong H, Wang MY (2016) Surgical outcomes of elderly patients with cervical spondylotic myelopathy: A meta-analysis of studies reporting on 2868 patients. Neurosurg Focus.

59. Whitehead SJ, Ali S (2010) Health outcomes in economic evaluation: The QALY and utilities. Br Med Bull 96: 5-21.

60. Carreon LY, Anderson PA, Traynelis VC, Mummaneni PV, Glassman SD (2013) Cost-effectiveness of single-level anterior cervical discectomy and fusion five years after surgery. Spine 38: 471-475.

61. Witiw CD, Tetreault LA, Smieliauskas F, Kopjar B, Massicotte EM, et al. (2017) Surgery for degenerative cervical myelopathy: A patient-centered quality of life and health economic evaluation. Spine J 17: 15-25.

62. Whitmore RG, Schwartz JS, Simmons S, Stein SC, Ghogawala Z (2012) Performing a cost analysis in spine outcomes research: Comparing ventral and dorsal approaches for cervical spondylotic myelopathy. Neurosurgery 70: 860867.

63. Fehlings MG, Jha NK, Hewson SM, Massicotte EM, Kopjar $B$, et al. (2012) Is surgery for cervical spondylotic myelopathy cost-effective? A cost-utility analysis based on data from the AOSpine North America prospective CSM study. J Neurosurg Spine.

64. Ghogawala Z, Martin B, Benzel ED, Dziura J, Magge SN, et al. (2011) Compartive effectiveness of ventral vs dorsal surgery for cervical spondylotic myelopathy. Neurosurgery 68: $622-630$

65. Fehlings MG, Wilson JR, Karadimas SK, Arnold PM, Kopjar B (2013) Clinical evaluation of a neuroprotective drug in patients with cervical spondylotic myelopathy undergoing surgical treatment: Design and rationale for the CSM-protect trial. Spine 38: 68-75.

66. Ganau M, Holly LT, Mizuno J, Fehlings MG (2018) Future directions and new technologies for the management of degenerative cervical myelopathy. Neurosurg Clin N Am 29: 185-193.

67. Arts MP, Wolfs JF, Corbin TP (2017) Porous silicon nitride spacers versus PEEK cages for anterior cervical discectomy and fusion: Clinical and radiological results of a single-blinded randomized controlled trial. Eur Spine J 26: 2372-2379. 